\title{
Implementasi Network Monitoring System Nagios dengan Event Handler dan Notifikasi Telegram Messenger
}

\author{
Tubagus Habibullah, Defiana Arnaldy \\ Program Studi Teknik Informatika \\ Jurusan Teknik Informatika dan Komputer \\ Politeknik Negeri Jakarta \\ tubagus.habibullah@gmail.com,defiana.arnaldy@tik.pnj.ac.id
}

Diterima: 9 Maret 2016. Disetujui: 16 April 2016. Dipublikasikan: Mei 2016

\begin{abstract}
Abstrak - Jaringan komputer sekarang ini sudah seperti sebuah kebutuhan, sehingga diperlukan adanya pemeliharaan dan kontrol teratur untuk menjamin agar jaringan dapat berjalan sebagaimana mestinya. Oleh sebab itu diperlukan sebuah fasilitas pendukung yaitu network monitoring system agar network administrator dapat memonitor suatu perangkat ataupun service pada suatu jaringan meskipun tidak di depan komputer secara langsung. Nagios merupakan salah satu aplikasi open source untuk network monitoring dan memiliki banyak fitur seperti monitoring, notifikasi alert, report, Event Handler dan lain-lain. Dalam penelitian ini diimplementasikan network monitoring system menggunakan Nagios dengan Event Handler dan notifikasi Telegram Messenger yang dapat melakukan monitoring perangkat dan services pada jaringan, dapat mengirimkan notifikasi melalui Telegram Messenger jika host atau service mengalami gangguan, serta dapat melakukan restart terhadap service yang gagal fungsi secara otomatis. Pengujian sistem dilakukan dengan menguji fungsionalitas kinerja sistem Nagios. Dari hasil pengujian didapatkan bahwa Nagios dapat mendeteksi perubahan status dengan selang waktu interval 5 menit untuk hosts dan 10 menit untuk services, notifikasi alert dapat terkirim kepada Group Telegram dengan selang waktu rata-rata 5-10 menit setelah Nagios mendeteksi adanya perubahan status down/recovery, dan Event Handler dapat melakukan restart terhadap services yang gagal fungsi dengan rata-rata waktu aksi 2 menit. Hal ini membuktikan bahwa Nagios dapat memonitoring perangkat dan services pada jaringan dengan baik sesuai dengan konfigurasi yang telah dilakukan.
\end{abstract}

Kata Kunci: event handler; Nagios; network monitoring system; notifikasi alert; telegram messenger.

\section{PENDAHULUAN}

Jaringan komputer bukanlah sesuatu yang baru dalam teknologi informasi dan komunikasi. Pada umumnya di setiap perusahaan, instansi, ataupun institusi pendidikan saat ini sudah menggunakan jaringan komputer untuk memperlancar arus informasi ataupun pertukaran datanya. Jaringan komputer saat ini menjadi sebuah kebutuhan, sehingga diperlukan adanya pemeliharaan dan kontrol yang teratur untuk menjamin agar jaringan dapat berjalan sebagaimana mestinya.

Untuk mencegah terjadinya gangguan yang terlalu lama umumnya seorang network administrator selalu mengawasi dan memantau kinerja jaringan komputer. Network administrator tidak mungkin terus menerus mengamati dan mengawasi di depan komputer secara langsung suatu perangkat ataupun service yang berjalan pada sebuah jaringan selama 24 jam. Oleh sebab itu diperlukan sebuah fasilitas pendukung yaitu netwok monitoring system agar network administrator dapat memonitor suatu perangkat ataupun service pada suatu jaringan meskipun tidak di depan komputer secara langsung.

Nagios merupakan salah satu aplikasi open source untuk network monitoring yang memiliki banyak pluginsdan dapat digunakan untuk memaksimalkan proses monitoring perangkat jaringan yang ada. Beberapa fitur yang dimiliki Nagios seperti monitoring, notifikasi alert, report, event handler, monitoring resource (CPU load, memory, status up/down, up time, data traffic, bandwidth) dan lain-lain. Nagios sendiri dapat dikonfigurasi sesuai dengan kebutuhan.

Salah satu fitur penting dalam Network Monitoring System adalah notifikasi alert, yaitu sistem pemberitahuan notifikasi kepada kontak network administrator jika sistem mendeteksi adanya permasalahan pada host maupun service. Pemberitahuan notifikasi dapat melalui berbagai media seperti email, sms, Telegram Messenger, dan lainnya. Selain fitur notifikasi alert, Network Monitoring System Nagios mempunyai fitur yang dapat melakukan restart terhadap service yang 
mengalami gangguan (error) secara otomatis. Berdasarkan latar belakang tersebut, maka dilakukan penelitian tentang "Implementasi Network Monitoring System Nagios dengan Event Handler dan Notifikasi Telegram Messenger".

Dalam penelitian ini yang menjadi fokus permasalahan adalah bagaimana mengimplementasikan penggunaan notifikasi status (up dan down) untuk host, status (unknown, critical, warning, dan recovery) untuk service melalui Telegram pada Nagios dan bagaimana memanfaatkan Event Handler untuk penanganan error pada service di Nagios.

Dalam penelitian ini terdapat beberapa batasan masalah, yaitu:

a. Perangkat yang dimonitoring adalah Mikrotik RouterBoard RB2011, Windows machine, dan Linux Ubuntu.

b. Monitoring pada Windows menggunakan addons Nagios yaitu NSClient++ yang harus diinstall.

c. Monitoring pada Linux Ubuntu menggunakan add-ons Nagios yaitu NRPE yang harus diinstall.

d. Notifikasi alert dikirim melalui Telegram ketika host dan service mengalami gangguan pada jaringan.

e. Event Handler menangani service Printer Spooler pada host Windows dan menangani service FTP dan SSH pada host Ubuntu.

\section{TINJAUAN PUSTAKA}

\section{A. Network Monitoring System}

NMS (Network Monitoring System) adalah kumpulan sistem yang memiliki tugas mengamati atau memonitor sistem-sistem di dalam jaringan terhadap kemungkinan terjadinya masalah-masalah pada sistem tersebut, untuk dapat dideteksi secara dini. Sebagai contoh, suatu monitoring sistem secara berkala menghubungi sebuah server untuk menjamin adanya respons dari server, jika tidak ada respons maka sistem monitoring akan mengirimkan pesan atau notifikasi kepada teknisi jaringan [1].

Pengiriman notifikasi pada sistem monitoring jaringan tentunya ditentukan oleh nilai ambang tertentu yang dapat ditentukan / setting nilainya pada setiap objek yang akan dimonitor sesuai dengan kebutuhan. Penentuan media notifikasi yang akan dipakai juga dapat ditentukan /setting dalam sebuah system monitoring jaringan, seperti melalui email ataupun media SMS [1].

Beberapa hal yang menyebabkan monitoring wajib dilakukan untuk sebuah network:

a. Untuk monitoring performance dari suatu jaringan. b. Mengetahui status (up/down) service dari host yang dimonitor secara realtime dengan sistem alert/alarm.

c. Media log dari service sehingga segala aktivitas host yang dimonitor akan tercatat.

\section{B. Nagios}

Nagios adalah sebuah tools untuk monitoring sistem. Yang berarti Nagios akan mengawasi komputer atau device di dalam jaringan dan memastikan bahwa komputer atau device bekerja dengan semestinya. Nagios secara teratur mengecek apakah mesin dalam keadaan baik atau tidak. Dan juga melakukan verifikasi berbagai macam service didalamnya dalam keadaan baik. [2]

Monitoring sistem di Nagios dibedakan menjadi dua kategori, yaitu hosts dan service. Hosts mewakilkan sebuah perangkat fisik atau virtual di dalam jaringan seperti server, router, workstation, printer, dll. Services adalah sebuah fungsi partikular, sebagai contoh, sebuah Secure Shell (SSH) server (sshd process pada perangkat) bisa didefinisikan sebaga service yang akan dimonitor. Setiap service pasti berhubungan dengan sebuah host yang menjalankannya [2].

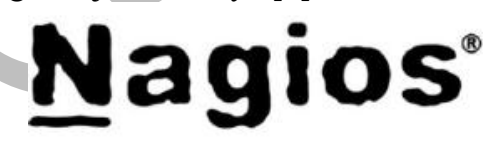

Gambar 1. Logo Nagios [3]

Berikut adalah fitur-fitur yang tersedia pada Nagios, antara lain:

a. Memonitor network services (SMTP, POP3, HTTP, PING, dan lain-lain)

b. Memonitor host resources (processor load, disk usage, dan lain-lain)

c. Desain plugins yang sederhana, yang memungkinkan pengguna untuk mengembangkan sendiri pemeriksaan terhadap servisnya.

d. Service checks yang paralel

e. Web interface yang fakultatif untuk melihat status network, urutan masalah dan notifikasi, $\log$ file, dan sebagainya.

f. Kemampuan untuk mendefinisikan kejadian yang ditangani selama servis atau host berlangsung untuk mempermudah pemecahan masalah

g. Perputaran log file yang otomatis

h. Notifikasi kontak ketika servis atau host terjadi masalah dan mendapat penanganan (via email, pager, sms, whatsapp, telegram atau method yang didefinisikan user)

\section{NRPE}

Nagios Remote Plugin Executor (NRPE) adalah sebuah add-on yang dirancang untuk mengizinkan plugins Nagios dapat berjalan pada 
remote machines (Linux/Unix). NRPE digunakan agar Nagios dapat memantau local resources (seperti CPU load, memory usage, etc.) pada remote machines. Oleh karena public resources pada suatu mesin tidak dipublikasikan kepada mesin lain, maka harus ada sebuah agent NRPE yang harus di-install pada remote machines Linux/Unix. [1]

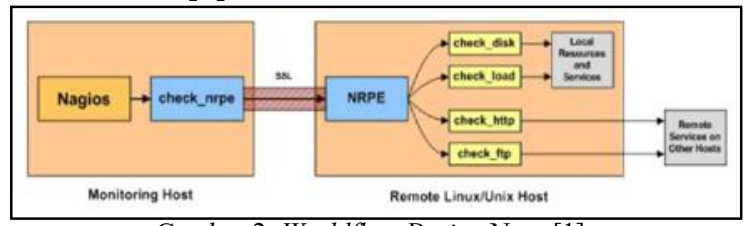

Gambar 2. Worldflow Design Nrpe [1]

Add-ons NRPE terdiri dari dua bagian:

a. Plugin check_nrpe, yang berada pada local monitoring machine.

b. NRPE Daemon, yang berjalan pada remote machines (Linux/Unix).

\section{NSClient ++}

NSClient++ adalah sebuah aplikasi sederhana yang powerfull dan merupakan daemon yang fleksibel untuk monitoring system [4]. NSClient++ merupakan jembatan penghubung antara server monitoring dengan host yang akan dimonitor. Pada dasarnya NSClient ++ bekerja pada tiga hal [5]:

a. Memungkinkan melakukan remote checks,

b. Memantau sistem secara realtime,

c. Mengatasi masalah yang terjadi.

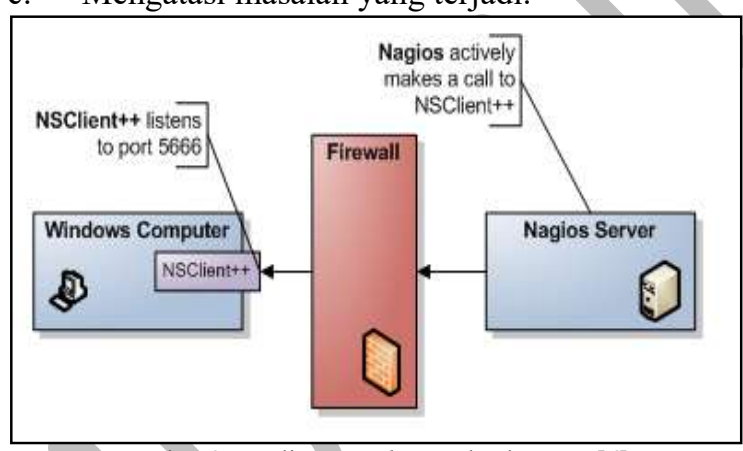

Gambar 3. Nsclient++ Plugin Check_Nrpe [6]

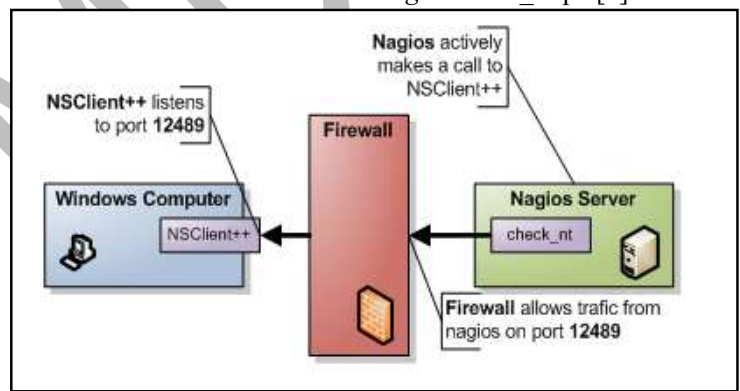

Gambar 4. Nsclient++ Dengan Plugin Check_Nt [6]

\section{E. Telegram Messenger \\ Telegram Messenger adalah aplikasi messaging yang berfokus pada kecepatan,}

keamanan, sederhana, dan dapat diunduh secara gratis. Telegram dapat digunakan di semua perangkat dalam satu akun dalam waktu yang sama. Telegram juga dapat mengirim pesan, foto, video, dan beberapa jenis file (doc, zip, mp3, dll), serta dapat membuat group hingga 5000 orang atau channel untuk broadcasting untuk khalayak terbatas. Beberapa fitur lain yang terdapat dalam Telegram Messenger: [7]

a. Enkripsi pesan, personal dan bussiness secret.

b. Menghapus pesan secara otomatis dengan timer.

c. Menyimpan media di dalam cloud.

d. Membangun sistem/tools sendiri dengan menggunakan API telegram.

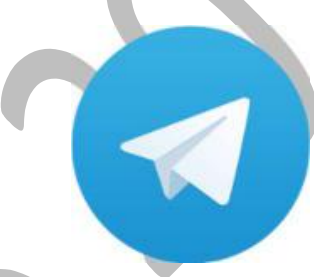

Gambar 5. Logo Telegram Messenger [7]

Salah satu fitur telegram yang berbeda dengan aplikasi messenger lainnya adalah Telegram menyediakan API (Application Programming Interface) yang terbuka $100 \%$ untuk publik yang ingin mengembangkan aplikasi menggunakan API Telegram.

F. Telegram APIs

Telegram mempunyai dua jenis APIs untuk developer, yaitu [7]:

a. Bot API

Bot API memungkinkan developer untuk menghubungkan Bot dengan sistem Telegram. Telegram Bots adalah sebuah akun khusus yang tidak memerlukan nomor telepon tambahan dalam pengaturannya. Akun ini berfungsi sebagai antarmuka untuk tempat berjalannya kode di pada suatu server.

b. Telegram API

Telegram API memungkinkan developer untuk membangun sendiri Telegram clients yang diinginkan. Telegram API terbuka 100\% untuk semua developer yang ingin membuat aplikasi dengan platform Telegram.

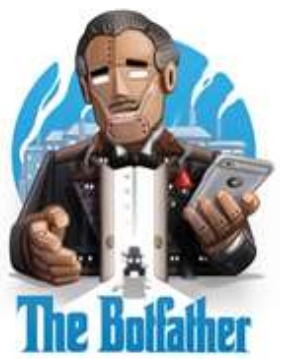

Gambar 6. The Botfather Telegram [7] 


\section{G. Telegram CLI}

Telegram CLI adalah sebuah aplikasi command-lineinterface yang digunakan untuk menjalankan Telegram. Telegram CLI memanfaatkan Telegram API dan Protokol Telegram (Mtproto) dalam penggunaannya. Daftar seluruh command yang ada pada Telegram CLI dapat dilihat dengan mengetik commandhelp di dalam tg-cli-session.

\section{PERANCANGAN DAN REALISASI}

\section{A. Perancangan Sistem}

Sistem yang dibangun adalah implementasi Network MonitoringSystem Nagios dengan Event Handler dan Notifikasi Telegram Messenger. Dengan sistem monitoring jaringan ini, monitoring machine dapat memonitor objek monitoring di dalam jaringan secara real-time, dapat mendeteksi status (up atau down) serta dapat mendeteksi adanya error atau masalah yang terjadi pada jaringan. Monitoring machine akan mengirimkan notifikasi alert melalui Telegram Messenger apabila host maupun service yang berada pada jaringan dalam keadaan down/error. Monitoring machine pun dapat menangani error pada service secara otomatis dengan Event Handler.

Gambar 7 menjelaskan bagaimana topologi perancangan sistem terdiri dari agent dan manager. Monitoring agent atau host disini adalah Windows, Linux dan Router. Sedangkan yang bertindak sebagai manager adalah PC server yang terintegrasi dengan NMS Nagios.

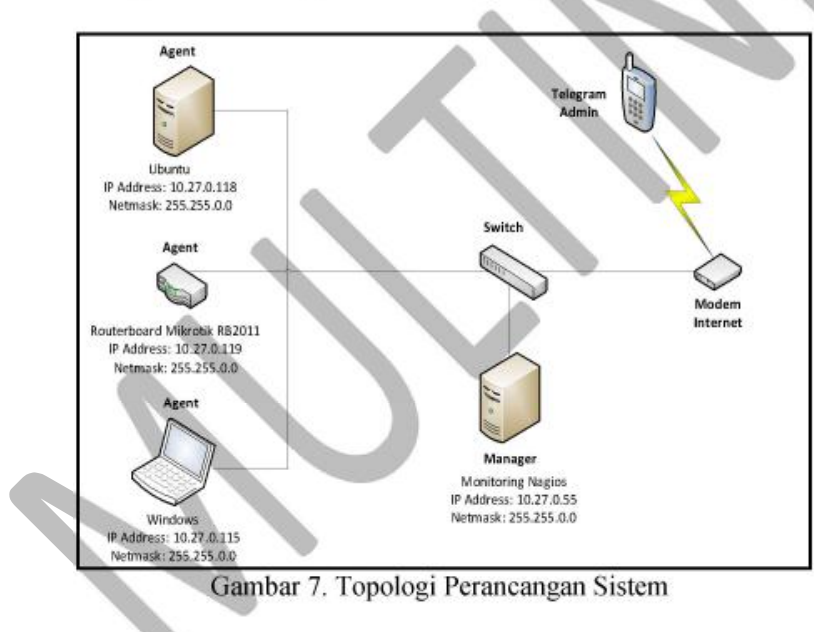

B. Cara kerja system

Cara kerja Network Monitoring System Nagios diuraikan menjadi 3 bagian, yaitu: Sistem monitoring host (Windows, Linux Ubuntu, dan Router), Sistem notifikasi alert dengan Telegram Messenger, dan Penanganan errorservice dengan Event Handler.
Terdapat beberapa host yang dimonitor oleh Network Monitoring System Nagios, yaitu:

a. Monitoring host Windows

Gambar 8 menjelaskan alur kerja monitoring host agar Nagios dapat memonitor privateservice dan local resources (CPU, Memory, Disk Space, Process, dan Services) pada windows machine. Windows machine membutuhkan suatu agent/daemon yang betindak seperti proxy antara plugin Nagios (check_nt) dan service yang akan dimonitor. Agent tersebut adalah NSClient++ yang di-install di sisi windows machine.

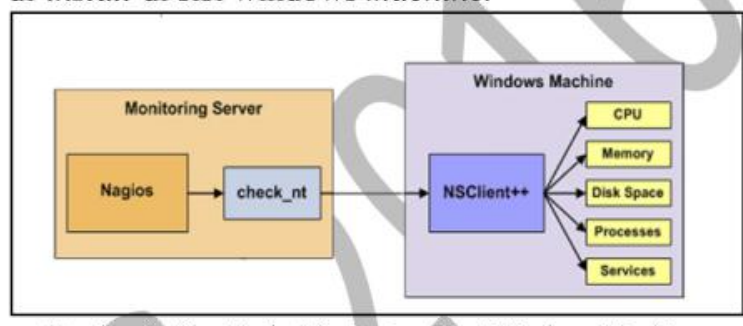

Gambar 8. Alur Kerja Monitoring Host Windows Machine

Cara kerja sistem monitoringhost windows:

a. Nagios mengeksekusi plugin check_nt dan akan menginformasikan service yang perlu diperiksa.

b. Plugin check_nt memanggil daemon NSClient++ pada remote host melalui SSLprotected connection (opsional).

c. Daemon NSClient++ menjalankan plugin Nagios (check_nt) yang sesuai untuk dilakukan pengecekan service atau resource.

d. Hasil pengecekan service dari daemon NSClient++ akan dikembalikan ke plugin check_nrpe, dimana hasil pengecekan tersebut akan diteruskan untuk diproses oleh Nagios.

b. Monitoring host Linux Ubuntu

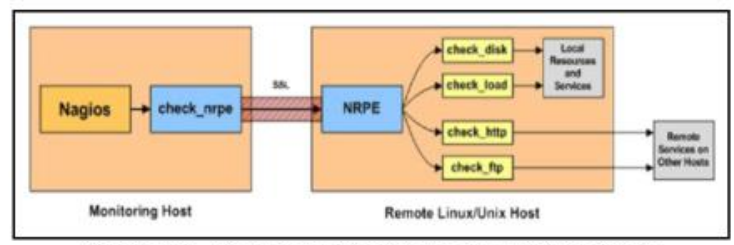

Gambar 9. Alur Kerja Monitoring Host Linux/Unix

Ubuntu merupakan salah satu dari distro linux/unix. Gambar 9 menjelaskan alur kerja monitoringhost agar Nagios dapat memonitor privateservice dan local resources pada linux/unix host. Sama seperti monitoringhost Windows, monitoring Linux/Unix pun membutuhkan suatu agent/daemon yang betindak seperti proxy antara plugin Nagios (check_nrpe) dan service yang akan dimonitor. Daemon tersebut adalah NRPE yang harus di-install di sisi linux/unix host. [7] 
Cara kerja sistem monitoring pada linux/unix host:

a. Nagios mengeksekusi plugin check_nrpe dan akan menginformasikan service yang perlu diperiksa.

b. Plugin check_nrpe memanggil NRPE Daemon pada remote host melalui SSL-protected connection (opsional).

c. NRPE Daemon menjalankan plugin Nagios (check_nrpe) yang sesuai untuk dilakukan pengecekan service atau resource.

d. Hasil pengecekan service dari NRPE Daemon akan dikembalikan ke plugin check_nrpe, dimana hasil pengecekan tersebut akan diteruskan untuk diproses oleh Nagios.

c. Monitoring Router

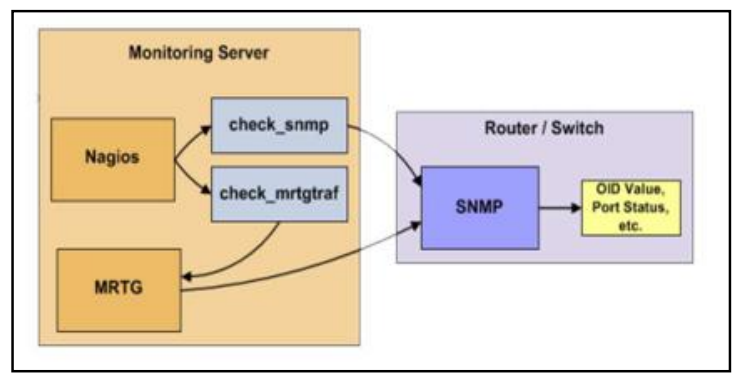

Gambar 10. Alur Kerja Sistem Monitoring Router/Switch

Gambar 10 menjelaskan alur kerja monitoring host agar Nagios dapat memonitor service/resource pada host router/switch. Nagios dapat memonitor resource/service dengan mengaktifkan dan melakukan konfigurasi SNMP pada host router/switch. Cara kerja sistem monitoring pada router host:

a. Nagios mengeksekusi plugin check_snmp dan check_mrtgtraf, kemudian menginformasikan service yang perlu diperiksa

b. Plugin check snmp akan mengambil data dari OID value pada router/switch yang sesuai dengan OID value resource/service yang perlu diperiksa.

c. Router/switch akan menginformasikan OID value yang sesuai untuk dilakukan pengecekan service/resource.

d. Hasil pengecekan service/resource dari router/switch akan dikembalikan ke plugin check snmp, dimana hasil pengecekan tersebut akan diteruskan untuk diproses oleh Nagios.

e. Plugins check_mrtg akan mengambil data dari MRTG (Multi Router Traffic Grapher) dimana MRTG mendapatkan data dari port status yang sesuai pada router.

f. Router/switch akan menginformasikan port status yang sesuai untuk dilakukan pengecekan traffic.

g. Hasil pengecekan traffic dari router/switch akan dikembalikan ke MRTG, lalu diteruskan ke plugin check_mrtg, dan hasil pengecekan tersebut akan diterukan untuk diproses oleh Nagios.

Cara kerja sistem notifikasi alert dengan Telegram Messenger pada Gambar 11:

a. Nagios mendeteksi adanya masalah/error pada service atau host.

b. Nagios melakukan pengecekan pada service atau host yang mengalami masalah/error.

c. Nagios mengirim data host atau service yang mengalami masalah/error berupa output pada script nagios_telegram.py

d. Script nagios_telegram.py menerima output dari Nagios berupa hasil error host atau service, yang selanjutnya akan dikirim melalui Bot Telegram dalam bentuk chat text yang berisi alertservice yang bermasalah ke Group Telegram Nagios.

e. Modem internet meneruskan proses untuk mengirimkan alert tersebut.

f. Notifikasi alert dikirim oleh sript nagios_telegram.py melalui modem internet.

g. Group telegram Nagios akan menerima chat text berupa notifikasi alert informasi host yang mengalami masalah/error.

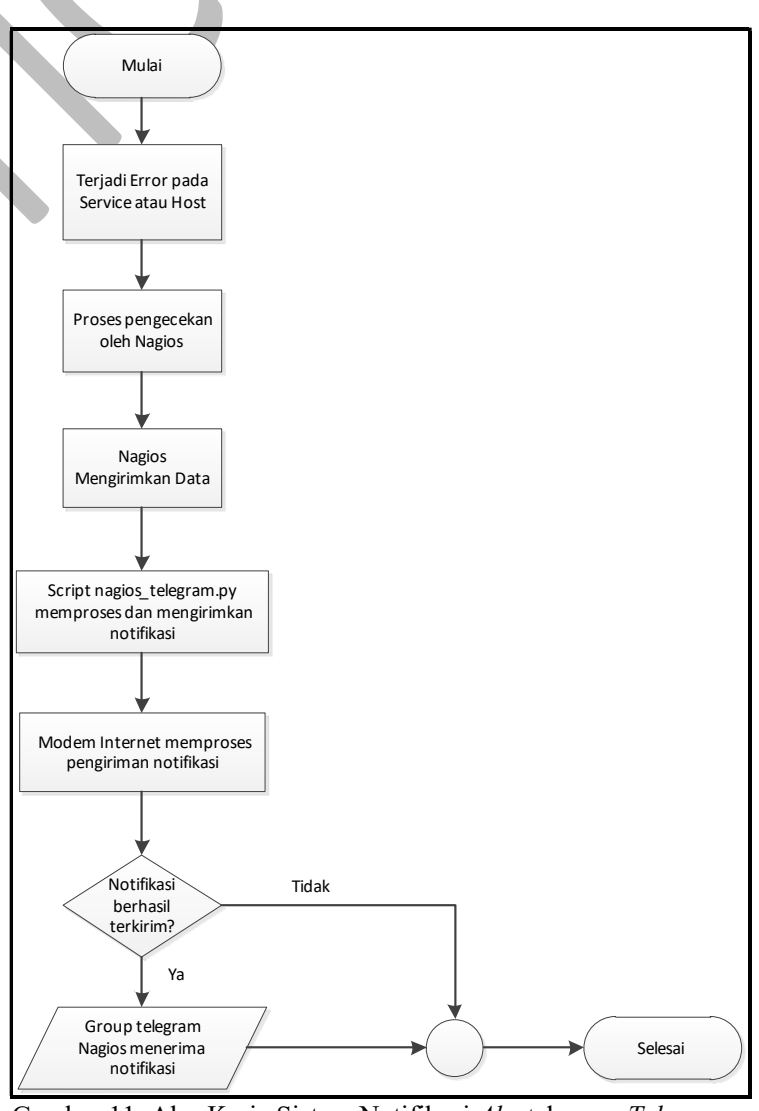

Gambar 11. Alur Kerja Sistem Notifikasi Alert dengan Telegram Messenger 


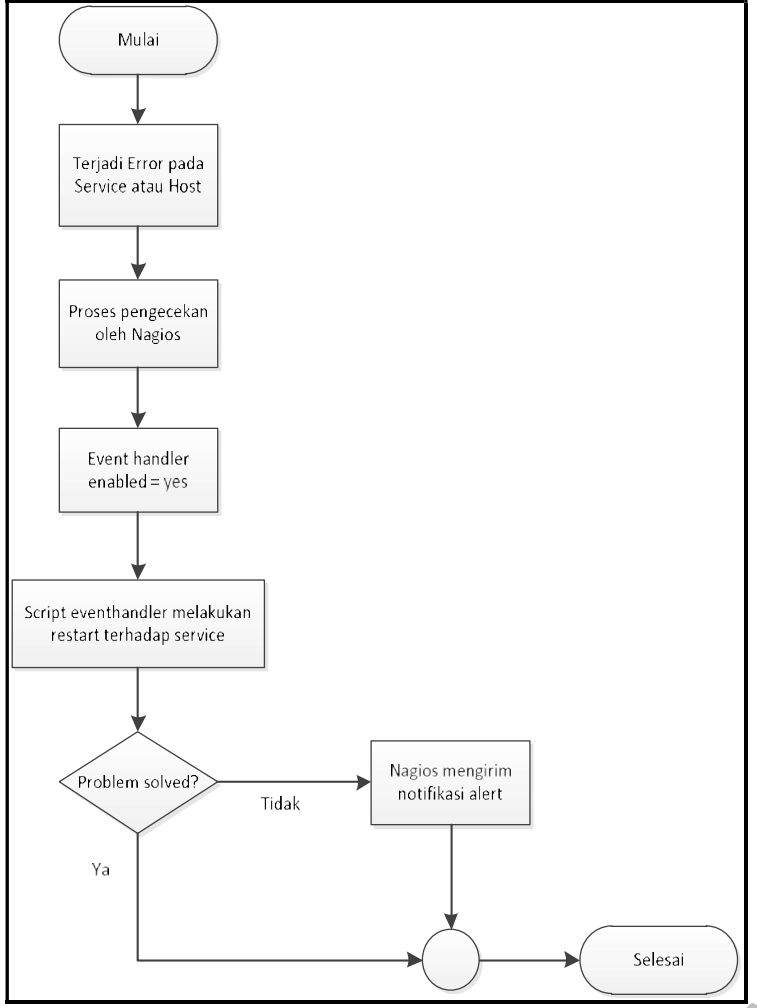

Gambar 12. Alur Kerja Sistem Event Handler

Gambar 12 menunjukkan cara kerja penanganan error pada service dengan Event Handler:

a. Nagios mendeteksi adanya masalah/error pada service atau host.

b. Nagios melakukan pengecekan pada service atau host yang mengalami masalah/error.

c. Nagios mendapatkan Event Handler diaktifkan di dalam service.

d. ScriptEvent Handler melakukan restart terhadap service yang mengalami masalah/error.

e. Ketika Event Handler tidak dapat melakukan tugasnya, dan service masih dalam keadaan error/bermasalah, maka Nagios akan mengirim notifikasi alert.

\section{IV.PEMBAHASAN}

\section{A. Pengujian}

Pengujian bertujuan untuk memastikan sistem agar dapat berjalan dengan semestinya. Pengujian dilakukan dengan metode Black Box, dimana dilakukan pengujian terhadap beberapa fungsi yang terdapat pada sistem. Terdapat 4 komponen utama yang diuji diantaranya adalah monitoringagent (NSClient++, NRPE, dan SNMP), web interface, notifikasi Telegram, dan Event Handler.

B. Prosedur pengujian

a. Pengujian monitoring agent terhadap fungsionalitas plugins Nagios:
1. Pengujian NSClient++ terhadap plugin check nt

2. Pengujian NRPE terhadap plugin check nrpe

3. Pengujian SNMP terhadap plugin check_snmp

b. Pengujian terhadap fungsionalitas web interface dilakukan pada autentikasi:

1. Pengujian hosts

2. Pengujian services

c. Pengujian terhadap fungsionalitas notifikasi Telegram

1. Pengujian notifikasi Telegram terhadap services

2. Pengujian notifikasi Telegram terhadap hosts

d. Pengujian terhadap fungsionalitas Event Handler

\section{Data hasil pengujian}

Hasil pengujian monitoring agent terhadap fungsionalitas plugins Nagios (NSClient++, NRPE, dan SNMP) akan dijelaskan pada Tabel 1 .

TABEL 1. PENGUJIAN MONITORING AGENT

\begin{tabular}{|l|l|l|l|l|}
\hline Pengujian & Plugins & Service & Output & Kesimpulan \\
\hline $\begin{array}{l}\text { NSClient }+ \\
+\end{array}$ & $\begin{array}{l}\text { Check_ } \\
\text { nt }\end{array}$ & $\begin{array}{l}\text { Check_ } \\
\text { load }\end{array}$ & $\begin{array}{l}\text { CPU Load } \\
4 \%\end{array}$ & Berhasil \\
\hline NRPE & $\begin{array}{l}\text { Check_ } \\
\text { nrpe }\end{array}$ & $\begin{array}{l}\text { Check_ } \\
\text { load }\end{array}$ & OK-load & Berhasil \\
\hline SNMP & $\begin{array}{l}\text { Check_ } \\
\text { snmp }\end{array}$ & Uptime & $\begin{array}{l}\text { SNMP OK } \\
\text { - Timeticks } \\
1: 31: 02\end{array}$ & Berhasil \\
& & & \\
\hline
\end{tabular}

Hasil pengujian autentikasi web interface dilakukan dengan pengujian benar dan salah yang dapat dilihat pada Tabel 2.

TABEL 2. PENGUJIAN AUTENTIKASI WEB INTEFACE

\begin{tabular}{|c|c|c|c|}
\hline \multicolumn{4}{|c|}{ Hasil Uji Benar } \\
\hline Input & $\begin{array}{l}\text { Hasil yang } \\
\text { Diharapkan }\end{array}$ & Output & $\begin{array}{l}\text { Kesi } \\
\text { mpul } \\
\text { an }\end{array}$ \\
\hline $\begin{array}{l}\text { Data login: } \\
\text { Username: } \\
\text { Nagiosadmi } \\
\mathrm{n} \\
\text { Password: } \\
\text { Admin }\end{array}$ & $\begin{array}{l}\text { Data login berupa } \\
\text { username dan } \\
\text { password yang } \\
\text { valid dapat masuk } \\
\text { ke dalam Web } \\
\text { Interface Nagios }\end{array}$ & $\begin{array}{l}\text { Input data } \\
\text { berhasil } \\
\text { dilakukan dan } \\
\text { masuk ke } \\
\text { dalam web } \\
\text { interface } \\
\end{array}$ & $\begin{array}{l}\text { Berh } \\
\text { asil } \\
\text { diuji }\end{array}$ \\
\hline \multicolumn{4}{|c|}{ Hasil Uji Salah } \\
\hline $\begin{array}{l}\text { Mengosong } \\
\text { kan } \\
\text { username } \\
\text { dan } \\
\text { password }\end{array}$ & $\begin{array}{l}\text { Tidak dapat Login } \\
\text { dan kembali pada } \\
\text { window } \\
\text { autentikasi }\end{array}$ & $\begin{array}{l}\text { Tidak dapat } \\
\text { login dan } \\
\text { diarahkan } \\
\text { kembali pada } \\
\text { window } \\
\text { autentikasi } \\
\end{array}$ & $\begin{array}{l}\text { Berh } \\
\text { asil } \\
\text { diuji }\end{array}$ \\
\hline
\end{tabular}

Pengujian hosts diuji pada host Ubuntu yang dilakukan sebanyak 5 kali dengan kondisi saat host "DOWN"dan kondisi saat host dilakukan recovery. Hasil pengujian service saat host Ubuntu dalam keadaan " $D O W N$ " dapat dilihat pada Tabel 3 dan "UP" pada Tabel 4. 
TABEL 3 DATA PENGUJIAN HOSTS UBUNTU "DOWN"

\begin{tabular}{cccc}
\hline Pengujian & $\begin{array}{c}\text { Waktu } \\
\text { Penonaktifan }\end{array}$ & $\begin{array}{c}\text { Waktu Deteksi } \\
\text { Nagios }\end{array}$ & Durasi* \\
\hline 1 & $11: 33: 03$ & $11: 33: 29$ & $0: 00: 26$ \\
2 & $12: 01: 34$ & $12: 01: 51$ & $0: 00: 17$ \\
3 & $12: 17: 14$ & $12: 17: 22$ & $0: 00: 08$ \\
4 & $12: 32: 35$ & $12: 33: 22$ & $0: 00: 47$ \\
5 & $12: 48: 16$ & $12: 48: 53$ & $0: 00: 37$ \\
\hline
\end{tabular}

*Durasi $=$ Selisih Waktu Deteksi Nagios dengan Waktu Penonaktifan

TABEL 4. DATA PENGUJIAN HOSTS UBUNTU " $U P$ "

\begin{tabular}{cccc}
\hline Pengujian & $\begin{array}{c}\text { Waktu } \\
\text { Recovery }\end{array}$ & $\begin{array}{c}\text { Waktu Deteksi } \\
\text { Nagios }\end{array}$ & Durasi* \\
\hline 1 & $11: 48: 23$ & $11: 48: 24$ & $0: 00: 01$ \\
2 & $12: 13: 25$ & $12: 13: 26$ & $0: 00: 01$ \\
3 & $12: 29: 34$ & $12: 29: 47$ & $0: 00: 13$ \\
4 & $12: 44: 10$ & $12: 44: 11$ & $0: 00: 01$ \\
5 & $13: 01: 32$ & $13: 03: 27$ & $0: 01: 30$ \\
\hline
\end{tabular}

*Durasi $=$ Selisih Waktu Deteksi Nagios dengan Waktu

Recovery

Pengujian services diuji pada FTP dan HTTP yang dilakukan sebanyak 5 kali pengujian untuk masing-masing service dengan kondisi service mengalami gangguan/error dan kondisi service dilakukan recovery. Hasil pengujian service saat FTP dalam keadaan error/dinonaktifkan dapat dilihat pada Tabel 5.

TABEL 5. DATA PENGUJIAN SERVICE FTP "CRITICAL"

\begin{tabular}{cccc}
\hline Pengujian & $\begin{array}{c}\text { Waktu } \\
\text { Penonaktifan }\end{array}$ & $\begin{array}{c}\text { Waktu Deteksi } \\
\text { Nagios }\end{array}$ & Durasi* \\
\hline 1 & $13: 16: 47$ & $13: 24: 22$ & $0: 07: 35$ \\
2 & $13: 49: 08$ & $13: 58: 22$ & $0: 09: 14$ \\
3 & $14: 21: 08$ & $14: 22: 22$ & $0: 01: 14$ \\
4 & $16: 08: 14$ & $16: 16: 34$ & $0: 08: 20$ \\
5 & $16: 34: 27$ & $16: 42: 34$ & $0: 08: 07$ \\
\hline *Durasi $=$ Selisih Waktu Deteksi Nagios dengan Waktu
\end{tabular}

*Durasi $=$ Selisih Waktu Deteksi Nagios dengan Waktu

Penonaktifan

Selanjutnya service FTP dilakukan recovery/diaktifkan kembali. Hasil pengujian service saat service FTP diaktifkan kembali dijelaskan pada Tabel 6.

TABEL 6. DATA PENGUJIAN SERVICE FTP "OK”

\begin{tabular}{cccc}
\hline Pengujian & Waktu Recovery & $\begin{array}{c}\text { Waktu Deteksi } \\
\text { Nagios }\end{array}$ & Durasi* \\
\hline 1 & $13: 35: 23$ & $13: 38: 22$ & $0: 02: 59$ \\
2 & $14: 06: 35$ & $14: 12: 22$ & $0: 05: 47$ \\
3 & $14: 35: 33$ & $14: 36: 22$ & $0: 00: 49$ \\
4 & $16: 23: 39$ & $16: 30: 22$ & $0: 06: 43$ \\
5 & $16: 51: 33$ & $16: 54: 22$ & $0: 02: 49$ \\
\hline
\end{tabular}

*Durasi $=$ Selisih Waktu Deteksi Nagios dengan Waktu Recovery

Pengujian selanjutnya yaitu pada service HTTP. Hasil pengujian service saat HTTP mengalami dalam keadaan error/dinonaktifkan dijelaskan pada Tabel 7.
TABEL 7. DATA PENGUJIAN SERVICE HTTP "CRITICAL"

\begin{tabular}{cccc}
\hline Pengujian & $\begin{array}{c}\text { Waktu } \\
\text { Penonaktifan }\end{array}$ & $\begin{array}{c}\text { Waktu Deteksi } \\
\text { Nagios }\end{array}$ & Durasi* \\
\hline 1 & $13: 16: 47$ & $13: 25: 56$ & $0: 09: 09$ \\
2 & $13: 49: 08$ & $13: 49: 55$ & $0: 00: 47$ \\
3 & $14: 21: 08$ & $14: 23: 55$ & $0: 02: 47$ \\
4 & $16: 08: 14$ & $16: 17: 42$ & $0: 09: 28$ \\
5 & $16: 34: 27$ & $16: 41: 42$ & $0: 07: 15$ \\
\hline *Durasi = Selisih Waktu Deteksi Nagios dengan Waktu \\
Penonaktifan
\end{tabular}

Selanjutnya service HTTP dilakukan recovery/ diaktifkan kembali. Hasil pengujian service saat service HTTP diaktifkan kembali dijelaskan pada Tabel 8.

TABEL 8. DATA PENGUJIAN SERVICE HTTP “OK”

\begin{tabular}{cccc}
\hline Pengujian & $\begin{array}{c}\text { Waktu } \\
\text { Recovery }\end{array}$ & $\begin{array}{c}\text { Waktu Deteksi } \\
\text { Nagios }\end{array}$ & Durasi* \\
\hline 1 & $13: 35: 23$ & $13: 39: 55$ & $0: 04: 32$ \\
2 & $14: 06: 35$ & $14: 13: 55$ & $0: 07: 20$ \\
3 & $14: 35: 33$ & $14: 37: 55$ & $0: 02: 22$ \\
4 & $16: 23: 39$ & $16: 31: 42$ & $0: 08: 03$ \\
5 & $16: 51: 33$ & $16: 55: 42$ & $0: 04: 09$ \\
\hline
\end{tabular}

*Durasi $=$ Selisih Waktu Deteksi Nagios dengan Waktu

Recovery

Hasil pengujian notifikasi terhadap hosts merupakan lanjutan dari hasil pengujian hosts pada Ubuntu.Hasil pengujian host saat Nagios mengirim notifikasi pada perubahan status host Ubuntu “DOWN" dapat dilihat pada Tabel 9.

TABEL 9. DATA PENGUJIAN NOTIFIKASI TERHADAP HOST UBUNTU "DOWN"

\begin{tabular}{cccc}
\hline Pengujian & $\begin{array}{c}\text { Waktu } \\
\text { Deteksi } \\
\text { Nagios }\end{array}$ & $\begin{array}{c}\text { Waktu Pengiriman } \\
\text { Notifikasi }\end{array}$ & Durasi* \\
\hline 1 & $11: 33: 29$ & $11: 40: 56$ & $0: 07: 27$ \\
2 & $12: 01: 51$ & $12: 07: 53$ & $0: 06: 02$ \\
3 & $12: 17: 22$ & $12: 25: 54$ & $0: 08: 32$ \\
4 & $12: 33: 22$ & $12: 41: 53$ & $0: 08: 31$ \\
5 & $12: 48: 53$ & $12: 58: 17$ & $0: 09: 24$ \\
\hline
\end{tabular}

*Durasi $=$ Selisih Waktu Pengiriman Notifikasi dengan Waktu Deteksi Nagios

Selanjutnya saat host Ubuntu dilakukan recovery/diaktifkan kembali dan Nagios mendeteksi perubahan status "UP". Hasil pengujian host saat Nagios mengirim notifikasi pada perubahan status "UP" host Ubuntu dijelaskan pada Tabel 10. Hasil pengujian notifikasi terhadap services merupakan lanjutan dari hasil pengujian services pada FTP dan HTTP. Hasil pengujian service FTP saat Nagios mengirim notifikasi pada perubahan status "CRITICAL" service FTP dapat dilihat pada Tabel 11. 
TABEL 10. DATA PENGUJIAN NOTIFIKASI TERHADAP HOSTS UBUNTU "UP"

\begin{tabular}{cccc}
\hline $\begin{array}{c}\text { Penguji } \\
\text { an }\end{array}$ & $\begin{array}{c}\text { Waktu Deteksi } \\
\text { Nagios }\end{array}$ & $\begin{array}{c}\text { Waktu } \\
\text { Pengiriman } \\
\text { Notifikasi }\end{array}$ & $\begin{array}{c}\text { Durasi } \\
*\end{array}$ \\
\hline 1 & $11: 48: 24$ & $11: 48: 24$ & $0: 00: 00$ \\
2 & $12: 13: 25$ & $12: 13: 22$ & $0: 00: 00$ \\
3 & $12: 29: 51$ & $12: 29: 51$ & $0: 00: 00$ \\
4 & $12: 44: 15$ & $12: 44: 15$ & $0: 00: 00$ \\
5 & $13: 03: 27$ & $13: 03: 27$ & $0: 00: 00$ \\
\hline *Durasi = Selisih Waktu Pengiriman Notifikasi dengan Waktu
\end{tabular}

Deteksi Nagios

TABEL 11. DATA PENGUJIAN NOTIFIKASI TERHADAP SERVICE FTP "CRITICAL"

\begin{tabular}{cccc}
\hline \multirow{2}{*}{ Pengujian } & $\begin{array}{c}\text { Waktu } \\
\text { Deteksi } \\
\text { Nagios }\end{array}$ & $\begin{array}{c}\text { Waktu Pengiriman } \\
\text { Notifikasi }\end{array}$ & Durasi* \\
\hline 1 & $13: 24: 22$ & $13: 28: 22$ & $00: 04: 00$ \\
2 & $13: 58: 22$ & $14: 02: 22$ & $00: 04: 00$ \\
3 & $14: 22: 22$ & $14: 26: 22$ & $00: 04: 00$ \\
4 & $16: 16: 34$ & $16: 20: 34$ & $00: 04: 00$ \\
5 & $16: 42: 34$ & $16: 44: 34$ & $00: 04: 00$ \\
\hline *Durasi = Selisih Waktu Pengiriman Notifikasi dengan Waktu \\
Deteksi Nagios
\end{tabular}

Selanjutnya saat service FTP dilakukan recovery/diaktifkan kembali dan Nagios mendeteksi perubahan status "OK". Hasil pengujian service saat Nagios mengirim notifikasi pada perubahan status service FTP "OK" dapat dilihat pada Tabel 12.

TABEL 12. DATA PENGUJIAN NOTIFIKASI TERHADAP

\begin{tabular}{cccc}
\multicolumn{4}{c}{ SERVICE FTP "OK" } \\
\hline Pengujian & $\begin{array}{c}\text { Waktu } \\
\text { Deteksi } \\
\text { Nagios }\end{array}$ & $\begin{array}{c}\text { Waktu } \\
\text { Pengiriman } \\
\text { Notifikasi }\end{array}$ & Durasi* \\
\hline 1 & $13: 38: 22$ & $13: 38: 22$ & $00: 00: 00$ \\
2 & $14: 12: 22$ & $14: 12: 22$ & $00: 00: 00$ \\
3 & $14: 36: 22$ & $14: 36: 22$ & $00: 00: 00$ \\
4 & $16: 30: 22$ & $16: 30: 22$ & $00: 00: 00$ \\
5 & $16: 54: 22$ & $16: 54: 22$ & $00: 00: 00$ \\
\hline
\end{tabular}

*Durasi $=$ Selisih Waktu Pengiriman Notifikasi dengan Waktu Deteksi Nagios

Pengujian selanjutnya yaitu pada service HTTP. Hasil pengujian service HTTP saat Nagios mengirim notifikasi pada perubahan status "CRITICAL" service HTTP dijelaskan pada Tabel 13.

TABEL 13. DATA PENGUJIAN NOTIFIKASI TERHADAP SERVICE HTTP "CRITICAL"

\begin{tabular}{cccc}
\hline \multirow{2}{*}{ Pengujian } & $\begin{array}{c}\text { Waktu } \\
\text { Deteksi } \\
\text { Nagios }\end{array}$ & $\begin{array}{c}\text { Waktu Pengiriman } \\
\text { Notifikasi }\end{array}$ & Durasi* $^{*}$ \\
\hline 1 & $13: 25: 56$ & $13: 29: 55$ & $00: 03: 59$ \\
2 & $13: 49: 55$ & $13: 53: 55$ & $00: 04: 00$ \\
3 & $14: 23: 55$ & $14: 27: 55$ & $00: 04: 00$ \\
4 & $16: 17: 42$ & $16: 21: 42$ & $00: 04: 00$ \\
5 & $16: 41: 42$ & $16: 45: 42$ & $00: 04: 00$ \\
\hline
\end{tabular}

*Durasi $=$ Selisih Waktu Pengiriman Notifikasi dengan Waktu Deteksi Nagios
Selanjutnya saat service HTTP dilakukan recovery/diaktifkan kembali dan Nagios mendeteksi perubahan status "OK". Hasil pengujian service saat Nagios mengirim notifikasi pada perubahan status service HTTP "OK" dijelaskan pada Tabel 14.

TABEL 14. DATA PENGUJIAN NOTIFIKASI TERHADAP SERVICE HTTP "OK"

\begin{tabular}{cccc}
\hline Pengujian & $\begin{array}{c}\text { Waktu Deteksi } \\
\text { Nagios }\end{array}$ & $\begin{array}{c}\text { Waktu } \\
\text { Pengiriman } \\
\text { Notifikasi }\end{array}$ & Durasi* \\
\hline 1 & $13: 39: 55$ & $13: 39: 55$ & $00: 00: 00$ \\
2 & $14: 13: 55$ & $14: 13: 55$ & $00: 00: 00$ \\
3 & $14: 37: 55$ & $14: 37: 55$ & $00: 00: 00$ \\
4 & $16: 31: 42$ & $16: 31: 42$ & $00: 00: 00$ \\
5 & $16: 55: 42$ & $16: 55: 42$ & $00: 00: 00$ \\
\hline *Durasi = Selisih WaktuPengiriman Notifikasi
\end{tabular}

*Durasi $=$ Selisih Waktu Pengiriman Notifikasi dengan Waktu Deteksi Nagios

Setelah dilakukan pengujian dari Event Handler, didapatkan hasil pengujian terhadap fungsionalitas Event Handler yang dilakukan melalui 5 kali pengujian terhadap service Printer Spooler pada host Windows-PC. Hasil pengujian dijelaskan pada Tabel 15.

TABEL 15. DATA PENGUJIAN EVENT HANDLER TERHADAP SERVICE PRINTER SPOOLER

\begin{tabular}{ccccc}
\hline & Waktu & $\begin{array}{c}\text { Waktu } \\
\text { Pengujian } \\
\text { Pensi } \\
\text { Nagios }\end{array}$ & $\begin{array}{c}\text { Waktu } \\
\text { Aksi } \\
\text { Event } \\
\text { Handler }\end{array}$ & Durasi* \\
\hline 1 & $13: 10: 57$ & $13: 13: 45$ & $13: 15: 45$ & $00: 02: 00$ \\
2 & $13: 32: 13$ & $13: 35: 45$ & $13: 37: 45$ & $00: 02: 00$ \\
3 & $14: 23: 41$ & $13: 27: 45$ & $14: 29: 45$ & $00: 02: 00$ \\
4 & $16: 34: 40$ & $16: 38: 35$ & - & - \\
5 & $16: 43: 31$ & $16: 47: 34$ & - & - \\
\hline
\end{tabular}

*Durasi $=$ Selisih Waktu Aksi Event Handler dengan Waktu Deteksi Nagios

D. Analisis Data/Evaluasi

\section{a. Analisis pengujian monitoring agent terhadap fungsionalitas plugins Nagios}

Berdasarkan hasil pengujian yang telah dilakukan, komunikasi plugins Nagios dengan monitoringagent NSClient++ pada Windows, NRPE pada Ubuntu, dan SNMP pada Router berhasil diuji. Dalam pengujian dapat dilihat bahwa masing-masing pengujian berhasil mendapatkan output berupa informasi service/resource sesuai dengan commmand plugins. Dengan demikian NSClient++, NRPE, dan SNMP pada monitoring host berfungsi dengan baik untuk memberikan informasi service/resource kepada Nagios untuk dilakukan monitoring.

b. Analisis pengujian terhadap fungsionalitas web interface

1) Analisis pengujian autentikasi web interface

Dari pengujian autentikasi web interface yang telah dilakukan didapatkan hasil yaitu autentikasi berhasil diuji. Hal ini didapat ketika melakukan input user name dan password 
dengan benar, user dapat masuk ke dalam halaman web interface Nagios, sedangkan ketika salah dalam inputusename dan password, user tidak dapat masuk ke halaman web interface Nagios dan dialihkan kembali pada window autentikasi.

\section{2) Analisis pengujian hosts}

Dari pengujian hosts yang telah dilakukan, didapatkan hasil yaitu Nagios berhasil diuji dengan mendeteksi perubahan keadaan status hosts secara real-time dengan hasil durasi deteksi Nagios. Durasi Nagios dalam mendeteksi perubahan status host tergantung pada konfigurasi check_interval.

Dari data pengujian hostUbuntu pada Tabel 3 dan Tabel 4 didapatkan durasi Nagios dalam mendeteksi perubahan status hosts dalam kondisi "DOWN" dan "UP" terjadi selama selang waktu kurang dari 5 menit. Kondisi tersebut sesuai dengan konfigurasi yang telah didefinisikan, yaitu check_interval pada host Ubuntu yang diatur 5 menit.

\section{3) Analisis pengujian services}

Dari pengujian services yang telah dilakukan, didapatkan hasil yaitu Nagios berhasil diuji dengan mendeteksi perubahan keadaan status services secara real-time dengan hasil durasi deteksi Nagios. Durasi Nagios dalam mendeteksi perubahan status services tergantung pada konfigurasi normal_check_interval.

Dari data pengujian services FTP pada Tabel 5 dan tabel 6 didapatkan durasi Nagios dalam mendeteksi perubahan status kedua services dalam kondisi "CRITICAL" dan "OK" terjadi selama selang waktu kurang dari 10 menit. Kondisi tersebut sesuai dengan konfigurasi yang telah didefinisikan, yaitu normal_check_interval pada service FTP dan HTTP yang diatur 10 menit.

c. Analisis pengujian terhadap fungsionalitas notifikasi Telegram

1) Analisis pengujian notifikasi hosts

Dari pengujian fungsionalitas notifikasi Telegram terhadap hosts yang telah dilakukan, didapatkan hasil yaitu Nagios berhasil diuji karena dapat mengirimkan pesan notifikasi alert kepada admin dalam Group Telegram "Nagios Alerts". Durasi saat Nagios melakukan pengiriman notifikasi tergantung pada konfigurasi retry_interval dan max_check_attempts.
Dari data pengujian notifikasi host Ubuntu dalam kondisi " $D O W N$ " pada Tabel 10 didapat durasi saat Nagios mendeteksi perubahan status "DOWN" sampai Nagios melakukan pengiriman notifikasi terjadi selama selang waktu kurang dari 10 menit. Kondisi tersebut sesuai dengan konfigurasi yang telah didefinisikan, yaitu max_check_attempts yang diatur 10 kali, dan retry_interval yang diatur 1 menit. Jadi, ketika Nagios mendeteksi perubahan status pada host Ubuntu(dalam keadaan soft state 1), Nagios melakukan pengecekan ulang dalam selang interval 1 menit yang dilakukan selama 10 kali sampai host dalam keadaan hard state.

Sedangkan dari data pengujian notifikasi host Ubuntu ketika dilakukan recovery sampai kondisi host menjadi "UP" pada Tabel 11 didapat hasil yaitu tidak ada selang waktu diantaranya. Kondisi tersebut dikarenakan ketika Nagios melakukan pengecekan pertama untuk memastikan perubahan status menjadi "UP", Nagios langsung mendeteksi bahwa keadaan tersebut sudah dalam keadaan hard state.

Notifikasi Nagios terhadap hosts melalui Telegram akan dikirim setelah Nagios mendeteksi kondisi hard state setelah dilakukan pengecekan berulang, hal ini dilakukan untuk memastikan kembali apakah kondisi hosts benar dalam keadaan bermasalah atau tidak sebelum dikirimkan kepada Group Telegram Admin. Pengiriman notifikasi Telegram pun bergantung pada koneksi internet di sisi server Nagios. Jika tidak ada koneksi internet/koneksi internet terputus, maka Nagios tidak akan mengirimkan notifikasi kepada Group Telegram Admin.

2) Analisis pengujian notifikasi services

Dari pengujian fungsionalitas notifikasi Telegram terhadap services yang telah dilakukan, didapatkan hasil yaitu Nagios berhasil diuji karena dapat mengirimkan pesan notifikasi alert kepada admin dalam Group Telegram "Nagios Alerts". Durasi saat Nagios melakukan pengiriman notifikasi tergantung pada konfigurasi retry_interval dan max_check_attempts.

Dari data pengujian notifikasi services FTP dalam kondisi "CRITICAL" pada Tabel 11 dan data pengujian notifikasi services HTTP dalam kondisi "CRITICAL" pada Tabel 13 didapat durasi saat Nagios mendeteksi perubahan status "CRITICAL" sampai Nagios 
melakukan pengiriman notifikasi terjadi selama selang waktu kurang dari 6 menit. Kondisi tersebut sesuai dengan konfigurasi yang telah didefinisikan, yaitu max_check_attempts yang diatur 3 kali, dan retry_interval yang diatur 2 menit. Jadi, ketika Nagios mendeteksi perubahan status "CRITICAL"pada services FTP dan HTTP(dalam keadaan soft state 1), Nagios melakukan pengecekan ulang dalam selang interval 2 menit yang dilakukan selama 3 kali sampai services dalam keadaan hard state. Setelah services dalam keadaan hard state, pada saat itulah Nagios mengirimkan notifikasi melalui Telegram Messenger.

Sedangkan dari data pengujian notifikasi service FTP dan HTTP ketika dilakukan recovery sampai kondisi services menjadi " $O K$ " pada Tabel 12 dan 14 didapat hasil yaitu tidak ada selang waktu diantaranya. Kondisi tersebut dikarenakan ketika Nagios melakukan pengecekan pertama untuk memastikan perubahan status services menjadi " $O K^{\prime}$ ", Nagios langsung mendeteksi bahwa keadaan tersebut sudah dalam keadan hard state.

Notifikasi Nagios terhadap services melalui Telegram akan dikirim setelah Nagios mendeteksi kondisi hard state setelah dilakukan pengecekan berulang, hal ini dilakukan untuk memastikan kembali apakah kondisi services benar dalam keadaan bermasalah atau tidak sebelum dikirimkan kepada Group Telegram Admin. Pengiriman notifikasi Telegram pun bergantung pada koneksi internet di sisi server Nagios. Jika tidak ada koneksi internet/koneksi internet terputus, maka Nagios tidak akan mengirimkan notifikasi kepada Group Telegram Admin.

\section{d. Analisis pengujian terhadap fungsionalitas Event Handler}

Dari pengujian Event Handler yang telah dilakukan, didapatkan hasil yaitu Nagios berhasil diuji karena dapat melakukan restart terhadap service yang mengalami masalah/error. Durasi saat eksekusi Event Handler terhadap service tergantung pada konfigurasi retry_interval dan max_check_attempts.

Dari data pengujian Event Handler pada Tabel 15 didapat durasi saat Nagios mendeteksi perubahan status service Printer Spooler "CRITICAL" sampai Event Handler melakukan aksi terhadap service terjadi selama selang waktu 26 menit. Kondisi tersebut sesuai dengan konfigurasi yang telah didefinisikan, yaitu max_check_attempts yang diatur adalah 4 kali, dan retry_interval yang diatur adalah 2 menit. Jadi, ketika Nagios mendeteksi adanya perubahan status pada service Printer Spooler, dalam interval 1 menit Event Handler melakukan eksekusi dan mengulangnya selama 4 kali sampai berhasil melakukan restart terhadap service.

Pada data hasil ke 3 dan 4 diketahui bahwa aksi Event Handler tidak dapat melakukan restart service setelah dilakukan pengulangan selama 4 kali. Hal tersebut dikarenakan remote hosts dalam keadaan mati yang menyebabkan remote agent (NSClient++) tidak dapat menjalankan service untuk melakukan restart service. Jika Event Handler tidak dapat melakukan aksinya untuk restart service bermasalah, maka Nagios akan meneruskannya agar dapat diproses untuk pengiriman notifikasi.

A. Kesimpulan

\section{PENUTUP}

a. Implementasi dari Network Monitoring System Nagios dapat memonitoring perangkat dan services yang ada pada jaringan dengan interval waktu pengecekan status pada host setiap 5 menit dan interval waktu pengecekan status pada service setiap10 menit.

b. Pemanfaatan Event Handler dengan melakukan restart service secara otomatis dapat menangani masalahyang terjadi pada service yang mengalami gangguan dengan waktu aksi Event Handler rata-rata 2 menit.

c. Penggunaan notifikasi alert Nagios dengan Telegram Messenger dapat mengirimkan notifikasi kepada network administrator berupa chat pada Group Telegram apabila host dan service pada suatu jaringan dalam kondisi mati (down) atau mengalami masalah dengan waktu rata-rata pengiriman notifikasi dari waktu Nagios mendeteksi perubahan status yaitu 5-10 menit. Pengiriman notifikasi alert dengan Telegram Messenger bergantung pada koneksi internet di sisi server Nagios.

\section{B. Saran}

a. Menambahkan target monitoring untuk melakukan monitor terhadap perangkat yang lain seperti printer, IP camera, dan lain-lain.

b. Menambahkan alert notifikasi lain, seperti audio notification alarm.

c. Menambahkan fitur Nagios lain seperti, nagmap untuk mapping menggunakan API Google Maps, NagiosQL, dan lain-lain. 


\section{REFERENSI}

[1] Prasetia, WC. 2012. "Implementasi Sistem Monitoring Jaringan Menggunakan Nagios dengan SMS Alert Menggunakan Ozeki NG SMS Gateway". Laporan Karya Ilmiah, Telkom University. Bandung

[2] Kocjan, Wojciech. 2014. Learning Nagios 4. Birmingham: Packt Publishing Ltd.

[3] Nagios. Nagios Core Documentation. 2016. https://www.nagios.org [30 Oktober 2015]
[4] Medin, Michael. 2016. Using NSClient++ from Nagios with check nt. https://docs.nsclient.org/tutorial/ nagios/check nt.html [29 April 2016]

[5] Ding Mei-Z̄hen, Huang Chen. 2015. Design And Implementation Of Network Monitoring System Based On Nagios. Information Technology And Informatization

[6] Galstad, Ethan. 2007. NRPE Documentation. https://assets.nagios.com/downloads/nagioscore/ docs/nrpe/NRPE.pdf [29 April 2016]

[7] SK. 2015. How to Install Nagios 4.1 in Ubuntu 15.04. Tamilnadu, India. http://www.unixmen.com/how-to-installnagios-4-1-in-ubuntu-15-04/ [30 Oktober 2015] 